\title{
Designing the Automatic Milking Farm in a Hot Climate
}

\author{
I. Halachmi \\ Agriculture Engineering Institution, \\ Agricultural Research Organization (A. R. O.), \\ Ministry of Agriculture and Rural Development, \\ The Volcani Center, P. O. Box 6, \\ Bet Dagan 50250, Israel
}

\begin{abstract}
A mathematical simulation model was used to assist 5 farmers in developing design criteria for inclusion of robotic milking systems in each farm situation. The barn layout influences arrivals of cows to the milking robot as well as other cow traffic and must be carefully planned. Each farmer had individual objectives and consequently unique design criteria that determined the optimal solution. Planning factors addressed by simulations on these farms included: 1) optimal cow cooling locations; 2) optimal facility allocation in expanding dairies; 3) concentrate feeder locations and feeding management; 4) number of feeders-based on expected rations; 5 ) use of a robot in an open cowshed without free stalls; 6) number of robots needed, currently and in the future; 7) eight robots working in harmony; 8) robot locations that allow for expansion; 9) floor space needed in each barn section including maternity and veterinary treatment areas; 10) location of bottlenecks that limit efficiency or expansion; and 11) cow traffic routine as affected by management practices, feed allocation, and farm layout. The simulation allowed farmers to receive a course in managing a "virtual robotic milking farm" before installation of the barn. Therefore, each could be more confident that his future barn would work properly under his unique local conditions and management practices. One farm checked 2 yr after construction achieved an average daily robot utilization of $84 \%$, nearly matching the $85 \%$ projected before the barn was built. Important variables considered in the simulations were facility allocation, cow space needed in each farm area, robot utilization, number of cows, milk yield, milk flow rate, feeding method and timing, robot location and orientation, and farm physical layout.
\end{abstract}

(Key words: robotic milking, dairy cow, farm design, simulation)

Abbreviation key: RMB = robotic milking barn.

Received July 21, 2002.

Accepted March 24, 2003.

E-mail: halachmi@volcani.agri.gov.il.

\section{INTRODUCTION}

Many factors are evaluated as a system when designing a barn, they include: feed delivery design, manure removal strategy (Fulhage, 1997), animal restraint, maternity areas (Fregonesi and Leaver, 2001), overcrowding, future expansion, grouping strategy, flow of animals and materials, farm physical layout, climate, winds, existing facility, labor and management requirements (Bickert et al., 1997), and cow cooling system (Flamenbaum et al., 1986, 1995).

All of these interrelated factors are important and should be taken into consideration, but it is usually difficult to quantify their effects on one another and on system productivity. A further complexity in the design of a robotic milking barn (RMB), in contrast to a conventional barn is that, whereas in the latter the milker brings the cows to a waiting area from where they have to enter the milking parlor, in an RMB a cow is expected to visit a milking stall voluntarily several times per day in response to her biological clock. As the barn layout strongly influences the cows' arrivals at the milking robot, it must be carefully planned. Figure 1 illustrates the immediate effect on the milk yield, of the number of visits to the robot. It can be seen that on $d$ -4 (4 $\mathrm{d}$ before downloading the data), due to a robot breakdown for around $3 \mathrm{~h}$, an average cow reduced her visiting frequency from 2.5 to 2.0 visits/d; the immediate effect was a milk yield reduction from 24 to $18 \mathrm{~kg} /$ cow per day; i.e., a total loss of $6 \mathrm{~kg}$ of milk $\times 250$ cows $\times 2 \mathrm{~d}=3000 \mathrm{~kg}$ of milk in only $2 \mathrm{~d}$. Thus, the long-term effect of the layout design can hardly be exaggerated, for instance a change in robot location, cow traffic arrangements, or feeding management that could have increased visiting frequency from 2.5 to 3 visits per cow per day (on average) throughout the year could have an enormous impact on the farm earnings.

However, robotic milking is a recent development, and it affects various factors that need to be taken into account when designing the barn layout: cow behavior (Ipema et al., 1988; Wierenga and Hopster, 1991; MetzStefanowska et al., 1992; Winter et al., 1992; Ketelaarde-Lauwere et al., 1996; Morita et al., 1996; Ketelaar- 

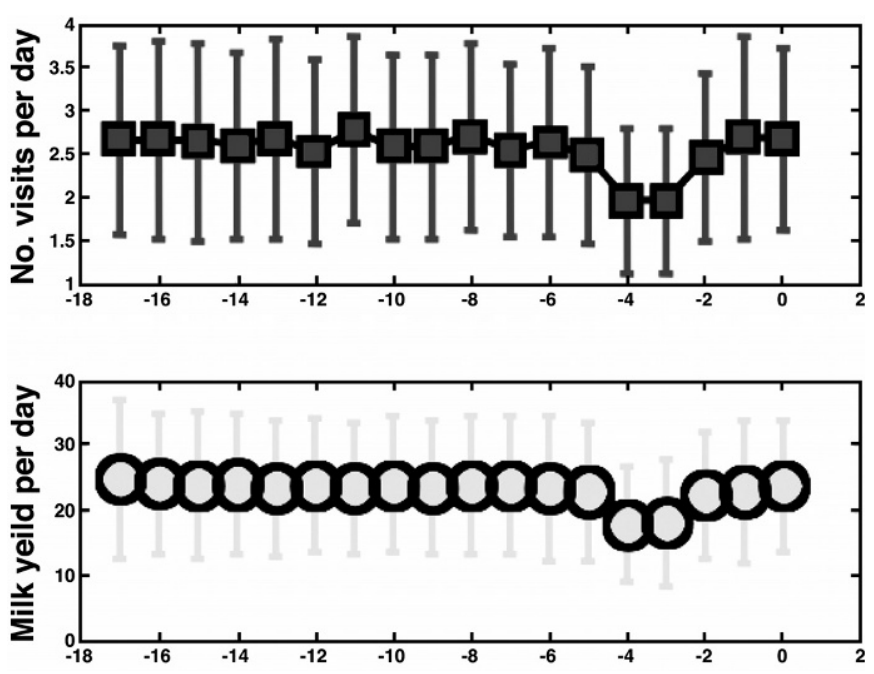

Figure 1. Short-term effect of fewer cow visits to the robots on the daily milk yield per cow, mean and STD of the 250 cows with four robots in farm $\mathrm{D}$. This effect was observed because of a $3-\mathrm{h}$ period during which the robot was not working, thereby reducing the number of milkings per day. (This figure can be viewed in color online.)

de-Lauwere, 1999; Stefanowska et al., 1991a, 1999b), farm routine, feeding procedures, cow traffic, milk quality (Klungel et al., 2000), and management practices (Swierstra and Smits, 1989; Uetake et al., 1997; Cooper and Parsons, 1998; Hogeveen et al., 1998; Ipema, 1998; Metz and Stefanowska, 2000; Parsons and Mottram, 2000; van Lenteren and Korsten, 2002; van't Land et al., 2002), the dynamic complexity of the system and the farmer's lack of experience with robotic milking working in his farm. Limited research has been conducted on the design of the entire RMB (the layout), but an integrated approach to planning was introduced in a previous study (Halachmi, 1999). By quantifying the usage of facilities as a stochastic process, Halachmi et al. (2000a) showed a way of using systems theory like queuing, computer simulation and Markov chains, when designing BMB. The new approach incorporates cow behavior (Halachmi et al., 2000a), farm management, the farm physical layout, scale drawings, a mathematical model (Halachmi et al., 2000b, 2003), and a computer simulation (Halachmi, 2000; Halachmi et al., 2001) that provides the integrated design tool required for optimizing this multidisciplinary system: the RMB. Simulation experiments enable equipment, management practices, and physical layout to be evaluated simultaneously, and potential design options to be highlighted before the barn is built; an initial design can be "fine-tuned" to produce a balanced system-a socalled optimal layout. The simulation tool was developed in a previous study (Halachmi, 2000; Halachmi et al., 2000a, 2000b, 2002, 2003). In the present study, the new tool was applied to the problem of designing the RMB; five case studies (involving real farms) are presented below: A) planning the cooling locations in open cowsheds-Samar farm; B) planning the facility allocation in expanding dairies-Faran farm; C) planning for eight robots to work in harmony-Maabarot farm; D) planning concentrate feeder location and feeding management-Bet-Alfa farm; E) planning the optimal layout for an open cowshed with a straw-bedded yard rather than free stalls or cubicle housing-Yavniel farm.

\section{MATERIALS AND METHODS- THE SIMULATION MODEL}

Halachmi et al. (2000a) concluded that cows' voluntary visits to the milking robot even out facility usage throughout the day and night, and so establish a continuous-time stochastic process. They quantified the intensity and sequence of the use of the facilities by the cows in a robotic milking barn, under conditions of maximum availability of facilities, in order to define the probabilistic nature of the process, as a first step towards optimizing the allocation of facilities. Figure 2 presents the individual resolution of data collected for the model. It can be seen that: 1) the cows' voluntary visits to the milking robot even out facility use throughout the day and night; 2) the cows spend much more time in the cubicles than in other facilities; 3 ) forage is consumed in meals throughout the day and night, each meal being divided into bouts (each vertical line indicates the starting or ending of one bout); and 4) a meal is a combination of several sequential activities (robotic milking, concentrate eating, forage eating, and drinking).

Halachmi et al. (2000b) described the development of a closed queuing network model for an RMB, to evaluate performance criteria, such as cow queue length, cow waiting time, and facility utilization. They analyzed cow 'flow' between barn facilities, by means of a Markov process. They assumed that each facility acts as a stochastically independent unit; therefore, they analyzed each facility separately, using queuing theory and an 'aspiration-level' model, which forms design criteria and provides an analysis of the overall performance of the barn (Figure 3).

The simulation model requires fewer simplifying assumptions than the network model. It also forms an interface between the eventual user and the mathematical level of the model, and therefore improves communication between barn operators and designers (see Figure 4). A modular approach is the basis of this simulation model (Halachmi, 2000). The system (barn) is broken down into five modules whose interactions generate the cow behavior in the barn and the "performance 


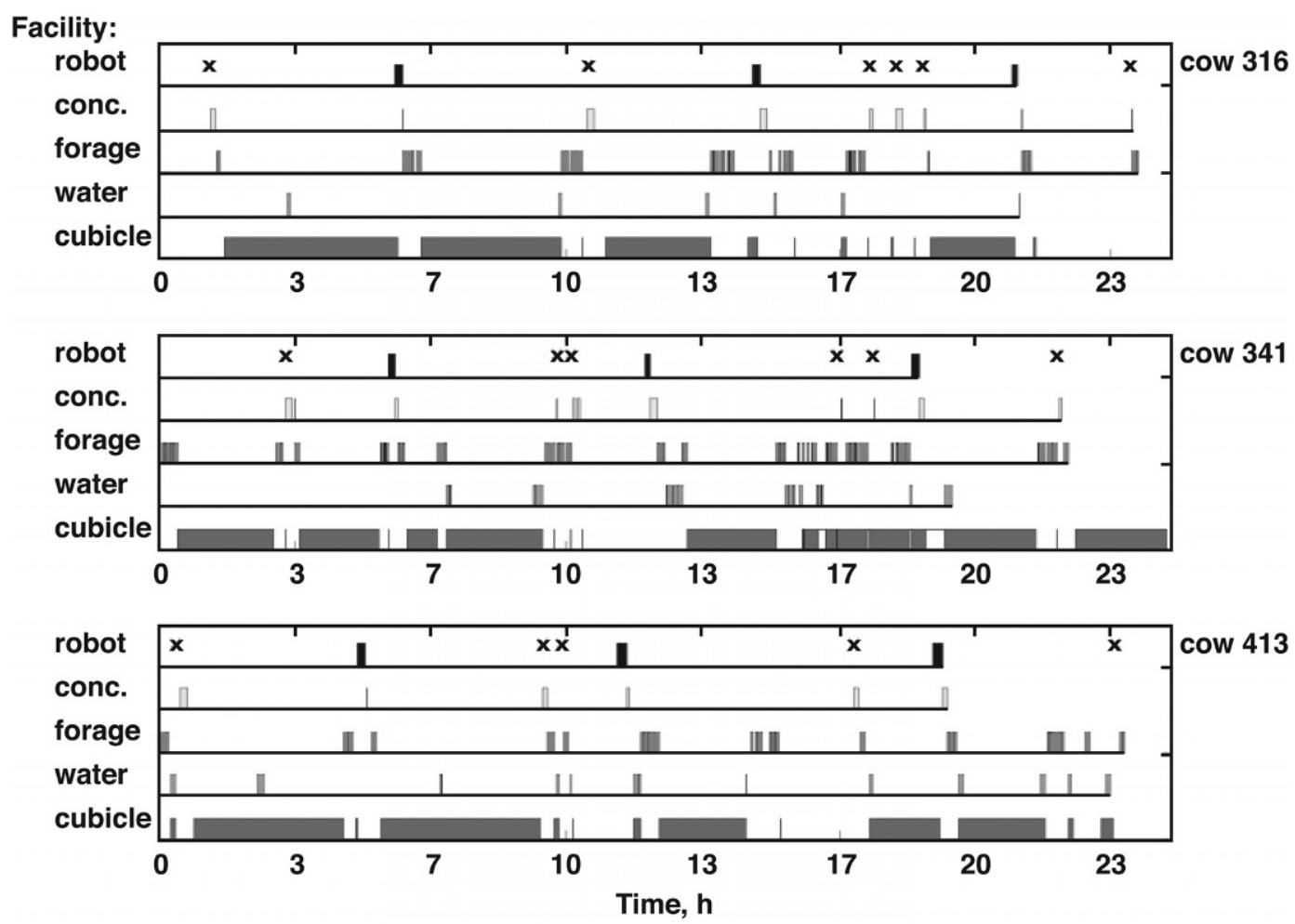

Figure 2. Three typical records of facilities usage by individual cows over a typical day; x, walking through the robot without being milked. Source Halachmi et al., 2000a. (This figure can be viewed in color online.)

of the barn;" they are the barn facilities (milking robot, concentrate feeder, forage lane, water troughs, and cubicles). Additional components can be added to the model as needed. A barn model addresses processes, i.e., the flow of cows through the barn facilities is studied, and the processes through which the various entities pass as they progress through the barn (system) are represented graphically. Cows are the primary entities in the model, and each has four important attributes: a number, a picture, a most recent milking time, and a most recent concentrate consumption time. When nesessary, details such as a cow's individual milk yield, social priority (dominance in the herd) can be added according to the decision to be made. In the animation, vivid colors indicate a cow's state: a green cow is in "working mode," i.e., occupying a facility, eating, being milked, or resting; a blue cow is in a "transit mode," i.e., either walking between facilities or idle; a queuing cow is red. Besides the analytical benefits such as optimizing the number of cubicles or robot location, it is important that model gives the farmer the assurance, before building, that the proposed design will actually meet his specified requirements. There are further advantages of the RMB simulation: animal welfare, simulation experiments do no harm to animals or to facilities and the objective of a study may be to estimate the effects of extreme conditions. Lower costs (although a simulation may require skilled manpower) are also seen; physical construction and refitting of different layouts are usually more expensive. Less time is needed to carry out an experiment, because it is often possible to simulate weeks, months, or even years in just a few seconds of computer time. Consequently, a long-range program (policy) may be tested in a relatively short time. Ease of replication: whereas a real barn rarely allows exact replication of experiments, simulation does. Simulation experiments enable factors that are uncontrollable in reality to be controlled. This helps to focus conclusions more sharply. Simulation yields a system-wide view of the effects of local changes. The impact of a change at a particular facility, on the facility itself may be predictable, but without simulation it might be impossible to predict the impact of this change on the performance of the whole system.

The main limitation of simulation lies in its ad hoc character: we observe the simulated responses only for the selected input combinations, i.e., there is no proof of the optimality of a solution. This is why the methodology starts with an analytical/mathematical optimization; Halachmi (2002) developed a metamodel for find- 

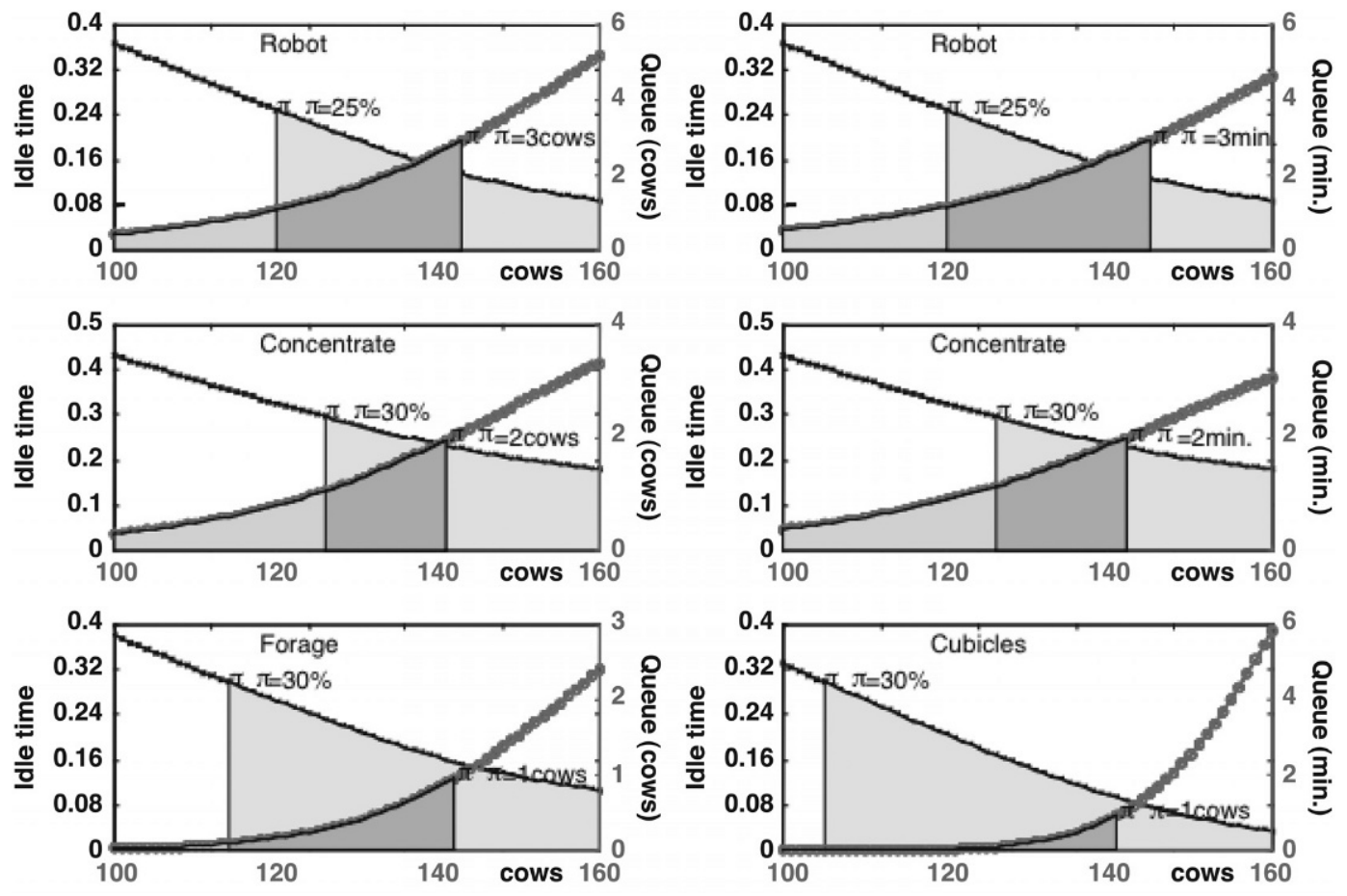

Figure 3. Performance of the entire barn: 6 concentrate feeders, 27 forage lane positions, 115 cubicles, and 4 milking robot stalls as function of number of cows (100 to 160). The system performance measures are waiting time, queue length and idle time. The robot's aspiration levels are average waiting time in the queue: $\alpha=3 \mathrm{~min}$, average queue length is $\beta=3$ cows, and robot idle time is less than $\gamma=$ $25 \%$, elsewhere, $\alpha=1 \frac{1}{2} \mathrm{~min}, \alpha=1$ cows and $\gamma=30 \%$. Source Halachmi et al., 2002a.

ing the initial layout that is to be optimized by means of a simulation.

Halachmi et al. (2001) compared data on real and simulated farms in a validation study in which measurements from real robotic farms ware compared with simulation data. The simulation model appeared to be a valid, accurate representation of the real system, under commercially feasible conditions. This hypothesis was tested statistically and was not rejected at $\alpha=2.5 \%$ (97.5\% confidence level). So the conclusion was that the model is a practical design tool that enables the designer to optimize facility allocation and barn layout.

The iterative design procedure generated numerical reports, drawings, and simulation responses to many "what-if" questions raised by the farm operators during the design process. For example, the simulation software addressed questions concerning the numbers of robots needed currently and in the future; the amount of floor space needed in each barn section, for maternity and veterinary treatments; the number of feeders, which depends on current and future feed rations; robot locations that allow for future expansion; location of bottlenecks that would prevent the introduction of additional cows into the same facility if the milking were, e.g., $15 \%$ faster (possibly as a result of cow breeding/ selection or upgraded robot software); recommenda- tions for cow traffic routines, which depend on varying the management practices, feeding routine and feed allocation. Because of the great number of possibilities, only a few tables and pictures were chosen for presentation in the present paper.

\section{FARM SITUATIONS AND RESULTS}

\section{Farm A: Planning the Cooling Locations}

Farm A is located in southeast Israel, a desert area. Four robots were to be installed in phase A, possibly to be followed a few years later by two or three additional robots (phase B). The average milk yields per cow were 10,500 and $11,500 \mathrm{~kg}$ during the first- and second-lactation years, respectively. Because of a limited budget, the designers were asked to retain the existing facilities and to minimize additional construction costs by the use of the existing cowshed (Figure 5), and the old milk store and office building. The design criteria were: up to five milkings per day; free-traffic routine; no cubicle housing; more than $20-\mathrm{m}^{2}$ floor space per cow; desired robot utilization of $85 \%$ including $5 \%$ refusals; up to four cows waiting in front of a robot. Two feeding options were: TMR feeding; and concentrate self-feeder with 3 to $6 \mathrm{~kg} / \mathrm{cow}$ per day, which the cows receive only after 


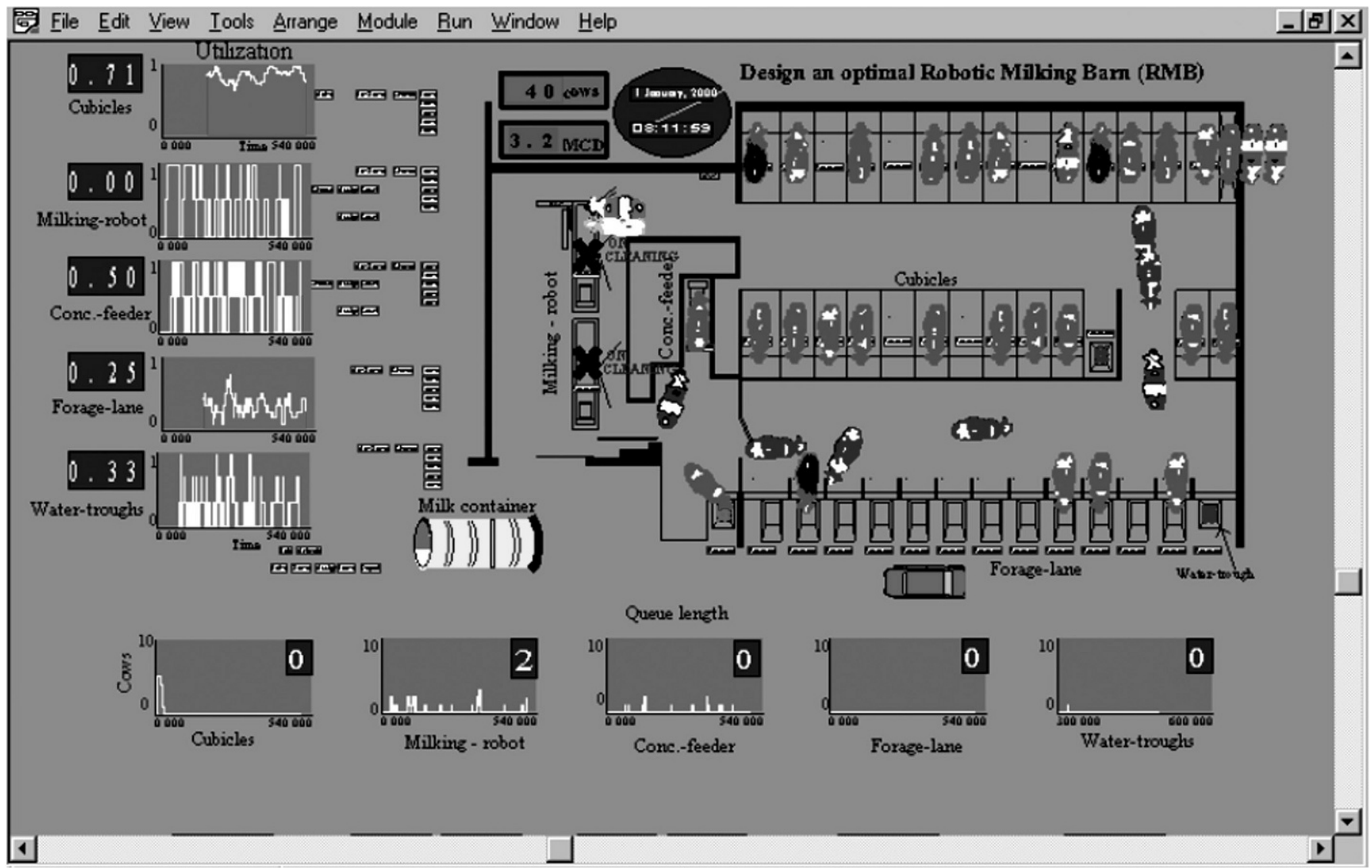

Figure 4. The simulation model ( 2 concentrate feeders, 12 forage-lane positions, three water troughs, 35 cubicles, 2 robot stalls, 40 cows) at $0812 \mathrm{~h}$. The clock at the top of the picture shows the simulated time. Next to the left, number of cows in the barn, and the expected milkings per cow per day (MCD). On the left side of the screen is a utilization graph for each facility. The graphs of the queue-length are located at the bottom. A digital number near a graph is the current value, whereas the graph keeps track of the historical values during the preceding $540 \mathrm{~min}$. The scale drawing is shown at the center of the computer screen. During the simulation run, all the cows and the milk tanker are shown moving as in real life, only speeded up. Vivid colors indicate a cow's state: a green cow is in a "working mode," occupying a facility, eating, being milked, or resting; a blue cow is in a "walking state," walking between facilities or idle; a cow in a queue, waiting for an unavailable facility is red. Two red cows in front of the robot are waiting in a virtual queue. The robot is "on cleaning," not available (marked by "X"), from 0800 to $0830 \mathrm{~h}$ daily. Every morning, around $0800 \mathrm{~h}$, the milk truck (the car icon) is driven slowly from the right side of the screen toward the milk tank, where it parks, empties the tank, and continues to a neighboring farm. Source: Halachmi, 2000. (This figure can be viewed in color online.)

being milked in the robot, the concentrate feeding time windows being set accordingly. The farm manager preferred to maintain a cow-cooling system with high-pressure sprinklers and mechanical ventilation. Cooling cows, naturally or by ventilation and sprinklers, is common in warm climates, both in Israel and elsewhere. However, in a conventional farm, the group is cooled in the milking-parlor waiting yard or in the feeding lane, to which the group rush after being milked, to consume forage feed. In a robotic milking-oriented design these options are not available, because only a few cows are waiting at the robot entrance at any moment, and they move toward the forage lane one-by-one, 24 $\mathrm{h}$ round the clock, according to their biological needs. Neither the farm designers (a highly experienced farm- building company), the farmers, nor the authors could find any scientifically reported experience with an RMB operating under similar hot-climate conditions; therefore, the new design methodology combined with simulation was applied.

The design process involved the simulation of four alternative layouts: 1) two robots in line at the side of the cowshed; 2) two robots side by side and close to one another at the side of the cowshed; 3 ) two robots at the center; 4) two robots at the center, oriented at $90^{\circ}$ to alternative 3 . The simulation runs were performed in the presence of the farm managers, the veterinarian, and the nutritionist. Then, after choosing the conceptual layout, we optimized the facility allocation by finetuning the chosen layout until we reached the so-called 


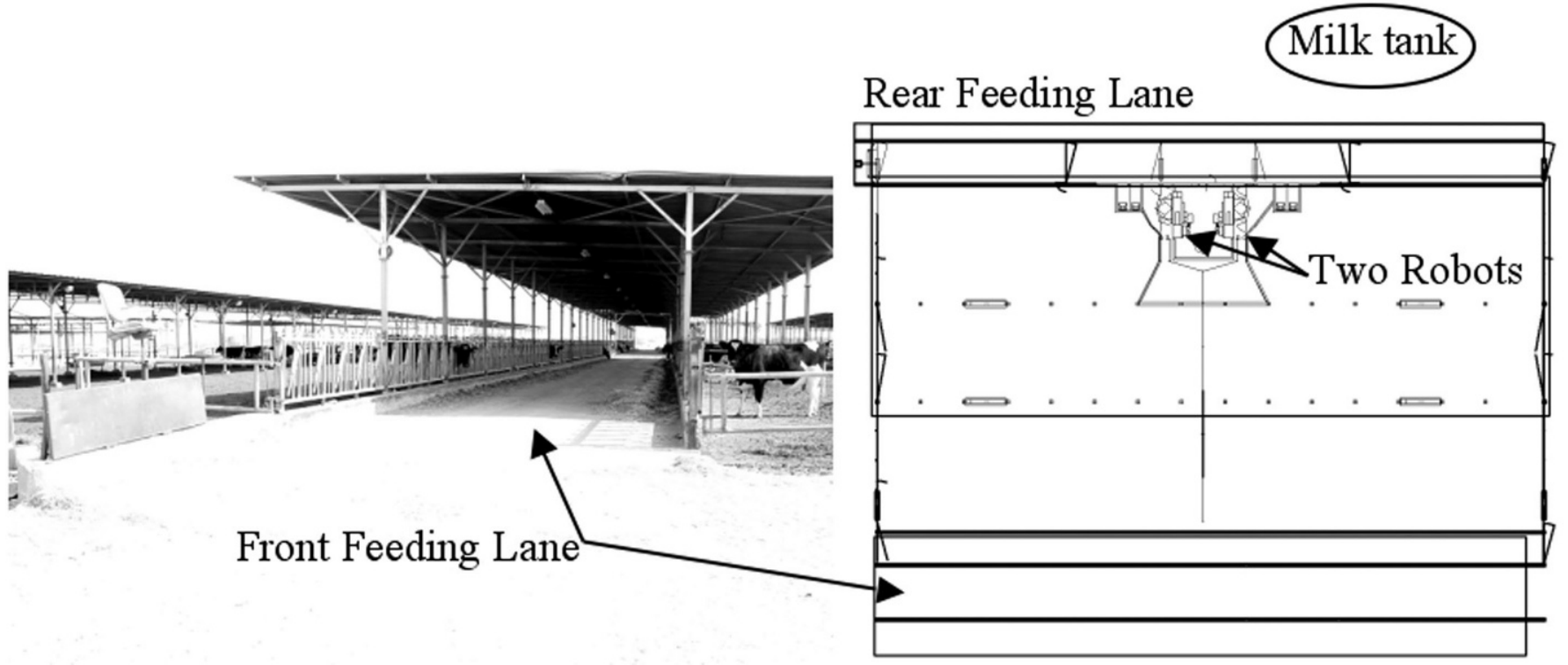

Figure 5. One cowshed in farm A, 120 to 140 cows in each cowshed; existing facility (left), the new design (right)—two robots located in the center of the cowshed. (This figure can be viewed in color online.)

optimal layout for the local conditions. The last design phase involved integrating the cooling system, which was evaluated in conjunction with the management practices, cow behavior, and the proposed physical layout of the barn. Figure 5 shows one of the existing cowsheds and the eventual so-called optimal design for that cowshed (two robots at the center; alternative 3 above).

Factors affecting the appropriate design of the cooling system in farm A can be seen in Table 1. Locating a cooling system at the robot entrance (as in a milkingparlor farm) is not effective, because it provides only $17.3 \mathrm{~min}$ of cooling per day. Location at the forage lane is somewhat more effective; it provides $244.6 \mathrm{~min}$ of cooling per day but, because of the long length of the forage lane, we have divided it into sections, each automatically activated by a photocell. An additional option that was simulated involved varying the area at the robot exit and installing a one-way gate after the selffeeder, thus providing a control tool that delayed specific cows and kept them longer in the area that was eventually chosen for cooling. Other data that emerged from the simulation runs indicated that if 5\% of the herd (per day) is directed by the robot to veterinary or insemination treatment between 0200 and $0800 \mathrm{~h}$, then the separation area should allow room for seven cows. From 0400 to $0800 \mathrm{~h}$ only four cows might arrive. The layout was designed accordingly.

\section{Farm B: Planning the Facility Allocation in Expanding Dairies}

Farm B was a new farm in southeast Israel, a few kilometers from the farmer's village, in the middle of a wide dry valley with prevailing west-east winds. The milk quota is 2.5 million $\mathrm{L}$ of milk per year, with the expectation of an additional $400,000 \mathrm{~L}$ in the near future. Today, with the milking parlor, the average annual milk yield is $10,500 \mathrm{~kg} / \mathrm{cow}$. The farmers set the following design criteria: 1) Robots were to perform up to five milkings per cow per day, with a desired robot utilization up to $87 \%$, including $5 \%$ of time for cleaning and cow refusals, and an average queue length of four cows. 2) Concentrate self-feeder was to provide up to 6 $\mathrm{kg}$ of concentrate feed within 6 -h intervals, with the remaining feed being given in the robot and in the TMR. The desired average feeder utilization was $70 \%$, with up to four cows waiting in the queue.

Table 2 presents two competing design concepts, which were examined in simulation runs of farm B. Both aim to produce an additional 400,000 L/yr. Concept 1 involves enlarging the herd by 40 cows, 20 in each cowshed, whereas concept 2 involves maintaining the same number of cows but raising their milk yield by means of superior nutrition. It can be seen that enlarging the yard to accommodate 20 additional cows raised the robot utilization from 78 to $89 \%$, extended the cow queuing time from 8 to $21 \mathrm{~min}$, and increased 
Table 1. Simulation results: Time spent at each barn facility (in minutes).

\begin{tabular}{|c|c|c|c|c|c|}
\hline Facility & $\begin{array}{l}\text { Daily } \\
\text { intervals } \\
(2 \mathrm{~h})\end{array}$ & $\begin{array}{l}\text { Mean visit } \\
\text { duration } \\
\text { (min) }\end{array}$ & $\begin{array}{l}\text { Max visit } \\
\text { duration } \\
\text { (min) }\end{array}$ & $\begin{array}{l}\text { Number of } \\
\text { visits per cow } \\
\text { per } 2 \text {-h interval }\end{array}$ & $\begin{array}{l}\text { Mean time/cow } \\
\text { per } 2 \text {-h interval at } \\
\text { each facility }\end{array}$ \\
\hline \multirow[t]{6}{*}{ Forage lane } & 00:00-02:00 & 17 & 62 & 0.73 & 12.4 \\
\hline & 08:00-10:00 & 33 & 118 & 0.55 & 18 \\
\hline & $10: 00-12: 00$ & 34 & 210 & 0.89 & 30 \\
\hline & $12: 00-14: 00$ & 26 & 250 & 0.90 & 23.4 \\
\hline & $20: 00-22: 00$ & 23 & 185 & 1.12 & 25.8 \\
\hline & $22: 00-24: 00$ & 17 & 94 & 1.07 & 18.1 \\
\hline \multirow{6}{*}{$\begin{array}{l}\text { Total } \\
\text { Lying }\end{array}$} & & & & 9.88 & 244.6 \\
\hline & $00: 00-02: 00$ & 68 & 215 & 0.77 & 52.4 \\
\hline & 02:00-08:00 & 98 & 527 & 2.33 & 228.4 \\
\hline & 08:00-10:00 & 104 & 538 & 0.71 & 73.8 \\
\hline & $20: 00-22: 00$ & 23 & 185 & 1.12 & 25.8 \\
\hline & $22: 00-24: 00$ & 17 & 94 & 1.07 & 18.1 \\
\hline Total & & & & 11.76 & 784.8 \\
\hline \multirow[t]{8}{*}{ Water trough after the robots } & 00:00-02:00 & 3.1 & 17 & 0.29 & 0.9 \\
\hline & 02:00-08:00 & 3.1 & 17 & 0.29 & 0.9 \\
\hline & 08:00-10:00 & 3.2 & 13 & 0.23 & 0.73 \\
\hline & $10: 00-12: 00$ & 3.1 & 15 & 0.48 & 1.5 \\
\hline & $12: 00-14: 00$ & 3.1 & 18 & 0.41 & 1.27 \\
\hline & $14: 00-16: 00$ & 3.2 & 16 & 0.40 & 1.28 \\
\hline & & : & : & & $:$ \\
\hline & $22: 00-24: 00$ & 3.2 & 14 & 0.46 & 1.47 \\
\hline Total & & & & 2.2 & 13.3 \\
\hline \multirow{2}{*}{ Other water troughs } & 00:00-02:00 & 3.2 & 15 & 0.48 & 1.53 \\
\hline & 02:00-08:00 & 3.1 & 17 & 1.33 & 4.12 \\
\hline \multirow{3}{*}{ Waiting yard before the robot } & $12: 00-14: 00$ & 3.8 & 25 & 0.66 & 2.5 \\
\hline & $14: 00-16: 00$ & 2.3 & 20 & 0.67 & 1.5 \\
\hline & $:$ & : & : & $:$ & $:$ \\
\hline Total & & & & 6.4 & 17.3 \\
\hline
\end{tabular}

Table 2. Simulated system performance in terms of robot utilization and cow queue length as a result of adding $400,000 \mathrm{~L} / \mathrm{yr}$ on farm B.

\begin{tabular}{llll}
\hline & & & $\begin{array}{l}\text { Cow queue length } \\
\text { (mean waiting time } \\
\text { and number of cows } \\
\text { waiting at the robot) }\end{array}$ \\
\hline Ref. & Scenario & $\begin{array}{l}\text { Robot } \\
\text { utilization }\end{array}$ & 8 min, 5 cows \\
Concept 1 & 120 cows, milk yield 10,500 L & $78 \%$ & 21 min, 13 cows \\
Concept 2 & 140 cows, milk yield 10,500 L & $89 \%$ & 15 min, 8 cows \\
\hline
\end{tabular}




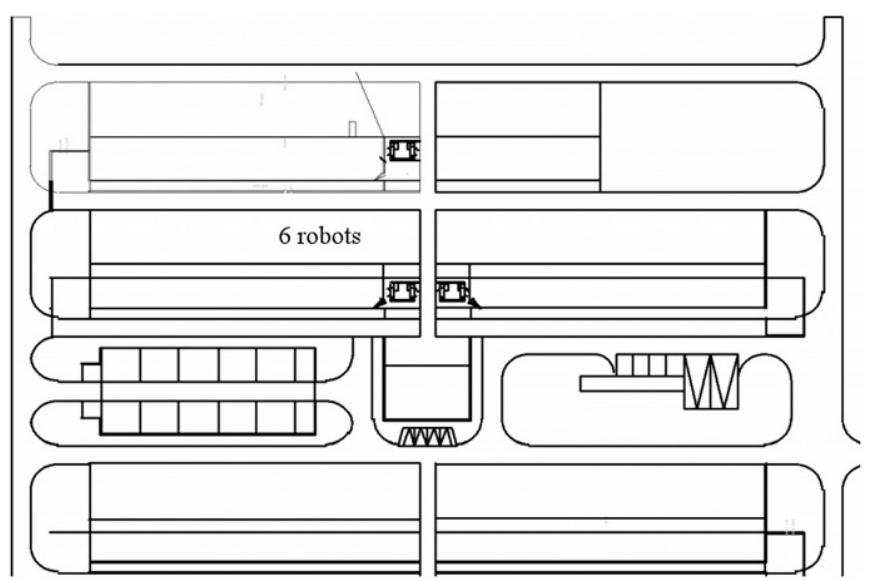

Figure 6. The layout of farm B, 120 to 140 cows in each group, open cowshed.

the number of cows in the queue from five to 13 . When only the milk yield per cow is raised (concept 2), the robot milking time is longer and, therefore, the robot utilization is also higher (86\%) and the queue length rises from five to eight cows. Because the farmer's initial design criteria included robot utilization of $87 \%$ and a queue length of up to eight cows, concept 2 was preferred and the entire layout of farm $\mathrm{B}$ was designed accordingly (Figure 6).

Table 3 presents some of the simulation experiments performed during the meetings with the farm managers, veterinarian, and nutritionist. It can be seen that the farm managers chose rather high robot utilization in their design options, obviously because of the rather high price of robots, and the most significant efficiency measures in their eyes were cow behavior in terms of queue length and waiting time in the queue.

\section{Farm C: Planning for Eight Robots to Work in Harmony, Ma'abarot Farm}

The farm was designed to hold approximately 1000 cows in milking, divided between two free-stall (cubicle) cowsheds. Each cowshed holds approximately 500 cows milked by eight robots. The grouping (and feeding) strategy, based on simulation results, led to the cows being divided into three groups of 120 to 140 cows (groups 1 to 3 ) and two groups of 55 to 70 cows (groups 4 and 5). Groups 4 and 5 were for training calving cows; and cows that need extra management time. The other groups included the rest of the cows. The milk yield per cow was $11,000 \mathrm{~L} / \mathrm{yr}$. The desired milking frequency is up to five milkings per cow per day, and the desired robot utilization was $85 \%$, with an average of up to four cows waiting in the queue. Up to $3 \mathrm{~kg}$ of concentrate feed was to be supplied in the self-feeder, the rest in the robot and in the TMR. Average cubicle utilization was up to $90 \%$. The separation yard should hold up to $10 \%$ of the cows, which should be separated automatically by the robot between midnight and $0800 \mathrm{~h}$, the latter being the start for visits by the veterinarian.

Taking the advantage of the size of the farm was the main issue in the planning of the eight robots of farm $\mathrm{C}$ (Ma'abarot farm). The management concept was that a large farm is not a collection of neighboring small farms, but is one single operation, a system. Table 4 presents three design options: alternative $\mathrm{i}$-robots are located in the center of the cowshed and there is a small separation area; alternative ii-robots in the center of the cowshed, large separation area; alternative iiirobots at the sides of the cowshed. It can be seen that alternative ii is preferred because it provides a larger separation area while keeping a low level of utilization of all the facilities. The chosen layout of that cowshed

Table 3. Other simulation results: Facility average utilization, cow queue length in terms of number of cows waiting for unavailable facility.

\begin{tabular}{|c|c|c|c|}
\hline Facility utilization & $\begin{array}{l}120 \text { cows } \\
10,000 \mathrm{~L} \\
\text { per cow } \\
\text { per year }\end{array}$ & $\begin{array}{l}140 \text { cows } \\
10,000 \mathrm{~L} \\
\text { per cow/ } \\
\text { y per year }\end{array}$ & $\begin{array}{l}120 \text { cows } \\
11,000 \mathrm{~L} \\
\text { per cow } \\
\text { per year }\end{array}$ \\
\hline Robot utilization & $71 \%$ & $76 \%$ & $75 \%$ \\
\hline Self-feeder utilization & $55 \%$ & $59 \%$ & $55 \%$ \\
\hline Forage lane utilization & $35 \%$ & $36 \%$ & $34 \%$ \\
\hline Water trough utilization & $30 \%$ & $30 \%$ & $30 \%$ \\
\hline \multicolumn{4}{|l|}{ Waiting time in a queue (minutes): } \\
\hline Milking robot (mean, maximum) & $5.3,44 \mathrm{~min}$ & $9.3,56$ & $6.8,53$ \\
\hline Concentrate self-feeder & $4.2,56$ & $5.8,56$ & $4.0,47$ \\
\hline Forage lane & 0,0 & 0,0 & 0,0 \\
\hline Water trough & 0,0 & 0,0 & 0,0 \\
\hline \multicolumn{4}{|l|}{ Number of cows waiting: } \\
\hline Milking robot (mean, maximum) & 2,19 & 3,24 & 2,18 \\
\hline Concentrate self-feeder & 1,15 & 2,20 & 1,15 \\
\hline Forage lane & 0,0 & 0,0 & 0,0 \\
\hline Water trough & 0,0 & 0,0 & 0,0 \\
\hline
\end{tabular}


Table 4. Results of simulation experiment of three competing designs of the eight-robot farm.

\begin{tabular}{|c|c|c|c|}
\hline & $\begin{array}{l}\text { i, Robots are located in the } \\
\text { center of the cowshed and } \\
\text { small separation area }\end{array}$ & $\begin{array}{l}\text { ii, Robots are located in the } \\
\text { center of the cowshed and } \\
\text { large separation area }\end{array}$ & $\begin{array}{l}\text { iii, Robots are located } \\
\text { in the sides of the } \\
\text { cowshed }\end{array}$ \\
\hline Number of cubicles & 111 & 112 & 95 \\
\hline Separation yard & $4.20 \times 4.00 \mathrm{~m}$ & $4.20 \times 9.0 \mathrm{~m}$ & $4.20 \times 4.0 \mathrm{~m}$ \\
\hline No. of water troughs & & & $\begin{array}{c}8 \\
7201\end{array}$ \\
\hline Robot utilization & $\begin{array}{l}73 \% \\
38 \%\end{array}$ & $73 \%$ & $73 \%$ \\
\hline \multicolumn{4}{|l|}{ Cow queue length: } \\
\hline Robot (mean, maximum) & $2.7,24$ cows & $2.8,24$ & $2.8,22$ \\
\hline Concentrate self feeder & $0.41,8$ & $0.4,24$ & $0.34,12$ \\
\hline Cubicles & 0,0 & 0,0 & $0.8,0-11$ \\
\hline
\end{tabular}

can be seen in Figure 7. Three groups (Figure 7a-c) comprised two Lely robots each, and the small groups (Figure 7d-e) consist of one robot each. The smaller group was intended for training fresh cows that were new to the robot, for milking cows that need more milking time or management time, and for human guests.

\section{Farm D: Planning Concentrate Feeder Location and Feeding Management, Bet-Alfa Farm}

In the late 1990s, half of the cowshed was built for two robots and was operating with limited success (for example, the annual milk yield had dropped by 800 to $1000 \mathrm{~L} / \mathrm{cow})$. Consequently, the farm manager ordered reengineering by simulation of the existing part as well as the design of a new facility with two additional robots. Therefore, the constraints included the use of the existing facilities such as the milk tank and the concen- trate container, which necessitated locating the robots at the side of the cowshed (in contrast to the solution found in farm C). There are 250 cows in one cowshed, divided into two groups, and the design criteria were fairly similar to those for farm C.

The design of Bet Alfa farm (D) emphasizes the location of the concentrate feeder. Initially, the concentrate feeder was located at the robot exit, and a one-way gate was supposed to prevent cows from reaching the selffeeder from the feeding alley, and to guide them through the robot. Figure 8 presents the farm design. Although the one-way gate was initially specified by the simulation software, it was inadvertently not installed, and this resulted in only 180 visits to the robot per day $(\mathrm{SD}=31)$ because of overcrowding at the robot exit (Figure 9), while the cows approached the self-feeder from the forage lane and not via the robot. Within 1 wk of the installation of the one-way gate, the number
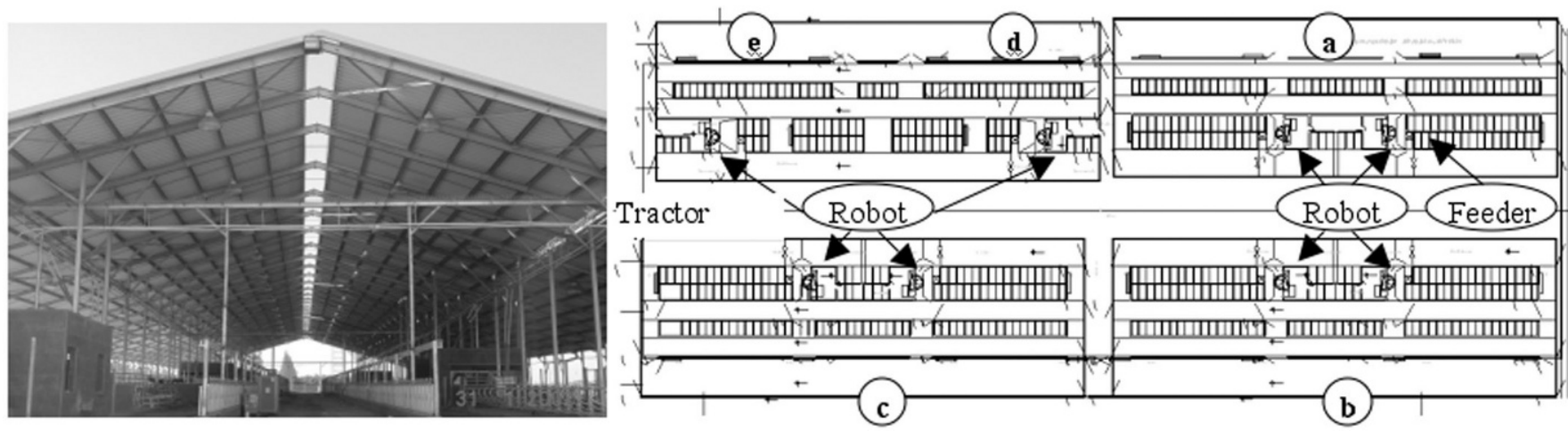

Figure 7. The chosen layout of farm C, 500 cows, free stalls, 8 robots, each robot followed by concentrate self-feeder, one-way gate that allows cows to reach the self-feeder only after visiting the robot, and a separation yard. The access to forage from cubicles is free. Three groups (a-c) comprised two Lely robots each, and the small groups $(d, e)$ consist of one robot each. The smaller group was intended for: training fresh cows, unfamiliar with the robot; for cows that need more milking time or management time; and for human guests. (This figure can be viewed in color online.) 


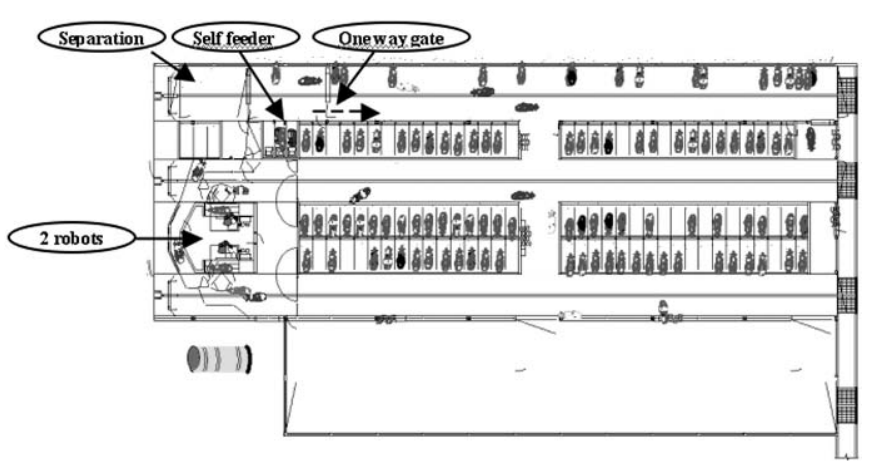

Figure 8. Farm D design, 280 cows with four robots, free stalls, each pair of robots followed by two or three concentrate self-feeders, a separation yard and a one-way gate that allows cows to reach the self-feeder only after visiting a robot. The access to forage cubicles is free. (This figure can be viewed in color online.)

of visits per robot per day rose above 220 ( $\mathrm{SD}=28$ ). This shows how a small, inexpensive change can have a huge impact on the performance of the entire system.

\section{Farm E: Planning Optimal Layout for an Open Cowshed (Strawyard), Yavniel Farm}

The cowshed was designed to hold 65 to 75 cows in milking, with about $20 \mathrm{~m}^{2}$ per cow. In the summer there is a problem of cows gathering in one corner, toward the wind direction, whereas $80 \%$ of the cowshed is vacant. Because of planned future expansion, we could not locate the robot on the windward side, but on the other side of the barn; the feeding routine was supposed to attract the cows to the robot even during the hot hours by the use of sophisticated schedules for feed allocation and location of the self-feeder at the robot exit.

Farm E, Yavniel farm presents the typical situation of cow arrivals during the hot hours. The farm was designed with an open cowshed (not a free-stall or cubicle system), and the author could not find any scientific documentation about combining a robot with an open cowshed. During the hot hours, around 1100 to 1400 $\mathrm{h}$, all the cows gathered at the far corner of the cowshed, the side remote from the robot, and none of them reach the robot at those hours (Figure 10). The solution, a combination of a cow cooling system and concentrate feeding management improved the situation: Figure 11 presents the performance of the 60 cows during $15 \mathrm{~d}$ before installing a cooling system and $15 \mathrm{~d}$ after installing it. There was 1 -wk break between the two periods, to allow the cows to get used to the fan noise. At 0600 $\mathrm{h}$, forage feed is distributed by a tractor-driven mixer wagon, and at $0600 \mathrm{~h}$ and again between 1200 to 1300 $\mathrm{h}$, the farmer brings in a few cows that have not visited the robot for more than $8 \mathrm{~h}$. The slowdown from 0400

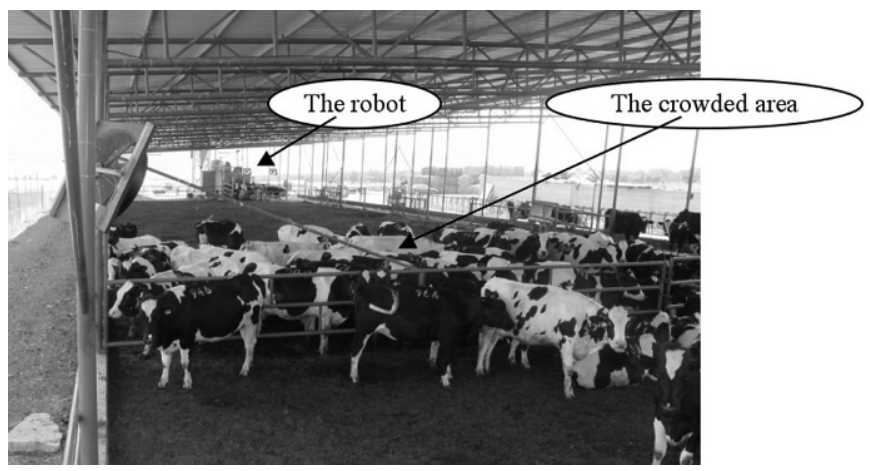

Figure 10. Farm E: open cowshed, built for around 70 cows with one single robot followed by concentrate self-feeder and separation yard immediately after the robot, a one-way gate that allows cows to reach the self-feeder only after visiting a robot. Access to the forage lane leading to and from the lying area is free.

to $0500 \mathrm{~h}$ is a well-known cow-behavior phenomenon

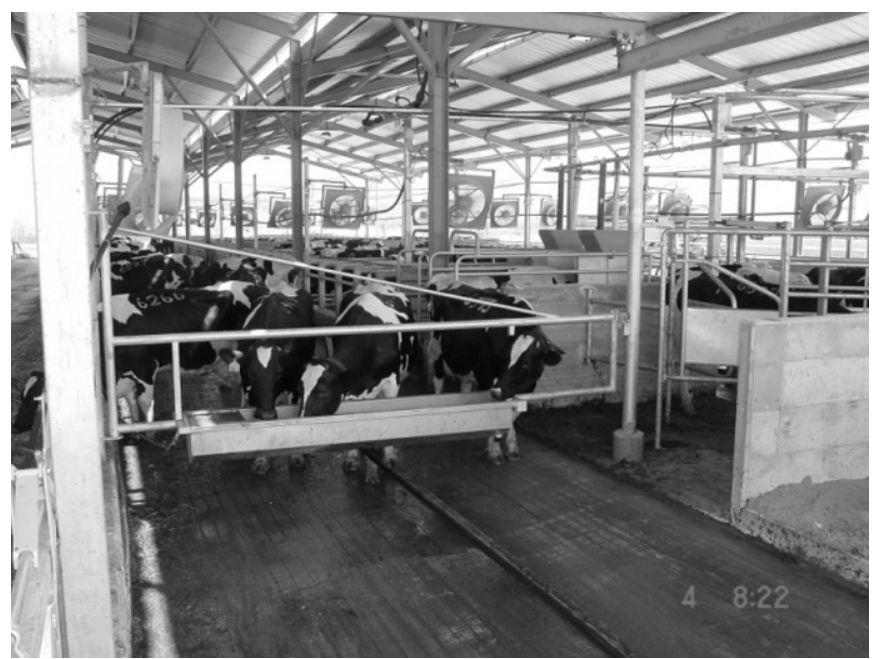

Figure 9. Overcrowding at the robot exit before installation of the one-way gate in Farm D.
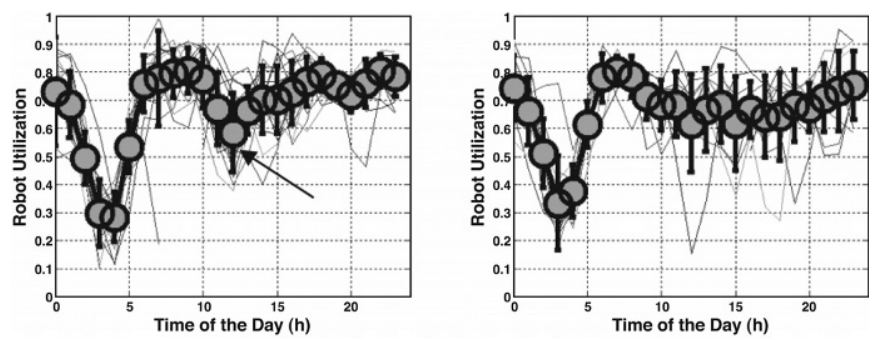

Figure 11. Robot utilization before (left) and after (right) installing cow cooling system. The arrow indicates the problematic hour around 1100 to $1200 \mathrm{~h}$ when the cows used to gather at the windward side, and not visit the robot. 
in a robotic milking barn (Halachmi, 2000). After installation, the average daily robot utilization measured during December 2002 and January 2003 was 84\%, nearly matching the $85 \%$ forecasted by the simulation before the barn was built.

\section{DISCUSSION}

This paper presented five robotic milking farm designs. By means of behavior-based simulation software (Halachmi, 2000; Halachmi et al., 2000a, 2000b) we achieved a so-called optimal layout, appropriate to local conditions. Layout, herd size, equipment, climate, breeding, management philosophy, etc., all influence the cows' behavior. Therefore, the optimum solution presented in this paper can be considered as optimal only for the particular barn for which it was designed. The methodology developed in this article is universally applicable; the parameters can be adjusted to every farmer, site, or milking robot. If the farm parameters are correct, simulation experiments can provide fairly accurate results such as proved earlier (Halachmi et al., 2001), in daily use by banks, supermarkets, distribution centers, and production floors. When rechecked in farm $\mathrm{E}$ above, the robot utilization was $84 \%$ in reality, while the simulation had forecasted $85 \%$ robot utilization 2 yr before the barn was built. The most important variables to consider in simulations are facility allocation, number of cows, milk yield, milk flow rate, feeding method, and timing, robot location and orientation, and physical layout.

From an economic point of view, the simulation offers reductions of about $40 \%$ in the number of forage-lane positions and of about $10 \%$ in the number of cubicles, without impairing the required level of animal welfare. From a cow perspective, water, feeding, resting, and milking areas are effectively available without long waiting times.

Water troughs are relatively cheap facilities, their function for high-yielding cows is physiologically important, and it is recommended, according to all criteria, to have troughs in each barn section. The function of the cubicles is also important: for resting, ruminating, and avoiding confrontation. A robot is relatively expensive, therefore its utilization should be relatively high. If we assume that the robot price is US $\$ 110,000$, then $1 \%$ utilization is worth about US $\$ 1300$ (assuming an average robot utilization of $85 \%$, i.e., US $\$ 110,000 / 85$ ). The design criteria were defined accordingly.

Robot companies update the robot software regularly, which results in better teat attachment, which, in turn, improves the robot capacity. This scenario was also analyzed from the point of view of the influence of the robot on the design of other parts of the barn. The correct robot location in the farm is especially important. It can prevent system bottlenecks that could arise from, e.g., wrong layout, poor location of gates, narrow passages, wrong water trough location that blocks another facility, or even from the cows' regular behavior and is, therefore, priceless in the design of a robotic milking farm.

\section{CONCLUSIONS}

Designing a robotic milking barn is a multidisciplinary task, which requires sophisticated tools to evaluate animal behavior, farm management, and the proposed building-all in combination. We have applied modeling and simulation to the design of few farms. Layout problems such as cooling the cows, traffic routines, future expansion, and feed management, can be efficiently tackled by using simulations. The simulation process including input from farmers and dairy consultants can help optimize dairy facility layout and efficiency before construction begins.

\section{REFERENCES}

Bickert, W. G., G. R. Bodman, B. J. Holmes, D. W. Kammel, J. M. Zulovich, and R. Stowell. 1997. Dairy Freestall Housing and Equipment, 6th ed. MidWest Plan Service, Ames, IA.

Cooper, K., and D. J. Parsons. 1998. A simulation model of an automatic milking system applying different management strategies. J. Agric. Eng. Res. 69:25-33.

Flamenbaum, I., D. Wolfenson, M. Mamen, and A. Berman. 1986. Cooling dairy cattle by a combination of sprinkling and forced ventilation and its implementation in the shelter system. J. Dairy Sci., 69:3140-3147.

Flamenbaum, I., D. Wolfenson, P. L. Kunz, M. Mamen, and A. Berman 1995. Interactions between body condition at calving and cooling of dairy cows during lactation in summer. J. Dairy Sci. 78:2221-2229.

Fregonesi, J. A., and J. D. Leaver. 2001. Behaviour, performance and health indicators of welfare for dairy cows housed in strawyard or cubicle systems. Livest. Prod. Sci. 68:205-216.

Fulhage, C. D. 1997. Manure management considerations for expanding dairy herds. J. Dairy Sci. 80:1872-1879.

Halachmi, I. 1999. Design methodology for a robotic milking barn: Modelling, simulation, validation, and optimization. Ph.D. thesis, Wageningen University, The Netherlands.

Halachmi, I. 2000. Designing the optimal robotic barn. Part 2: Behaviour-based simulation. J. Agric. Eng. Res. 77:67-79.

Halachmi, I., J. H. M. Metz, E. Maltz, A. A. Dijkhuizen, and L. Speelman. 2000a. Designing the optimal robotic barn, Part 1: Quantifying facility usage, J. Agric. Eng. Res. 76:37-49.

Halachmi, I., I. J. B. F Adan, J. van der Wal, J. A. P. Heesterbeek, and P. van Beek. 2000b. The design of robotic dairy barns using closed queuing networks. Eur. J. Oper. Res. 124:437-446.

Halachmi, I., A. Dzidic, J. H. M. Metz, L. Speelman, A. A. Dijkhuizen, and J. P. C. Kleijnen. 2001. Validation of simulation model for robotic milking barn design: case study. Eur. J. Oper. Res. 134:165-176.

Halachmi, I., I. J. B. F. Adan, J. van der Wal, P. van Beek, and J. A. P. Heesterbeek. 2003 Designing the optimal robotic barn, using queuing network model. Agric. Syst. 76:681-696.

Halachmi, I., J. H. M. Metz, A. van't Land, S. Halachmi, and J. P. C. Kleijnen. 2002. Optimal facility allocation in a robotic milking barn. Transact. ASAE 45:1539-1546. 
Hogeveen, H., A. J. H. van Lent, and C. J. Jagtenberg. 1998. Free and one-way cow traffic in combination with automatic milking. Pages 80-87 in Proc. 4th Int. Dairy Housing Conf. Am. Soc. Agric. Eng., St. Joseph, MI.

Ipema, A. H. 1998. Introduction and Experiences with Robotic Milking on Dairy Farms in the Netherlands. Technical Report No P 98-70, IMAG-DLO Wageningen, The Netherlands.

Ipema, A. H., H. K. Wierenga, J. Metz, A. C. Smits, and W. Rossing. 1988. The effect of automated milking and feeding on the production and behavior of dairy cows. Pages 1-24 in Automation of Feeding and Milking: Production, Health Behavior and Breeding. J. Unshelm and G. Schonmuth, eds. EAAP Publ. No 40 Pudoc, Wageningen, The Netherlands.

Ketelaar de Lauwere, C. C. 1999. Cow behaviour and managerial aspects of fully automatic milking in loose housing systems. Ph.D. thesis, Wageningen Agricultural University, The Netherlands.

Ketelaar-de Lauwere, C. C., S. Devir and J. H. M. Metz. 1996. The influence of social hierarcy on the time budget of cows and their visits to an automated milking system. Appl. Anim. Behav. Sci. 49:199-211.

Klungel, G. H., B. A. Slaghuis, and H. Hogeveen. 2000. The effect of the introduction of automatic milking systems on milk quality. J. Dairy Sci. 83:1998-2003.

Metz, J. H. M., and J. Stefanowska. 2000. Cow welfare in a precision dairy farming environment. 2nd Dutch-Japanese Workshop on Precision Dairy Farming, Nishinasuno, Japan.

Metz-Stefanowska, J., P. J. M. Huijsmans, P. H. Hogewerf, A. H. Ipema, and A. Keen. 1992. Behavior of cows before, during and after milking with an automatic milking systems. Pages 278-288 in Proc. Int. Symp. Prospects for Automatic Milking. A. H. Ipema, A. C. Lippus, J. H. M. Metz, and W. Rossing, eds. EAAP Publ. No 65 Pudoc, Wageningen, The Netherlands.

Morita S., S. Devir, C. C. Ketelaar de Lauwere, A. C. Smits, H. Hogeveen, and J. H. M. Metz. 1996. Effects of concentrate intake on subsequent roughage intake and eating behavior of cows in an automatic milking system. J. Dairy Sci. 79:1572-1580.
Parsons, D. J., and T. T. Mottram. 2000. An assessment of herd management aspects of robotic milking on UK dairy farms. Pages 212-220 in Robotic Milking International Symposium, Lelystad, The Netherlands.

Stefanowska, J., A. H. Ipema, and M. M. W. B. Hendriks. 1999a. The behavior of dairy cows in automatic milking system where selection for milking takes place in the milking stalls. Appl. Anim. Behav. Sci. 62:177-193.

Stefanowska, J., N. S. Tiliopoulos, A. H. Ipema, and M. M. W. B. Hendriks. 1999b. Dairy cow interactions with an automatic milking system starting with 'walk-through' selection. Appl. Anim. Behav. Sci. 63:177-193.

Swierstra, D., and A. C. Smits. 1989. Modern dairy farming with automatic milking system. Pages 927-932 in Agricultural Engineering. Vol. 2. A. D. Vincent and P. M. Grace, eds. A. A. Balkema Brookfield, Rotterdam, The Netherlands.

Uetake, K., J. F. Hurnik, and L. Johnson. 1997. Effect of music on voluntary approach of dairy cows to an automatic milking system. Appl. Anim. Behav. Sci. 53:175-182.

van't Land, A., A. C. van Lenteren, E. van Schooten, C. Bouwmans, D. J. Gravesteyn, and P. Hink. 2002. Management issues in relation to optimal robotic dairy. Pages III-70 to III-75 in The 1st North American Conference on Robotic Milking, Toronto, Canada.

van Lenteren, A. C., and G. Korsten. 2002. Sub-optimal cow and barn condition and its effects on the visiting frequency at the milking robot. Pages III-64 to III-69 in The 1st North American Conference on Robotic Milking, Toronto, Canada.

Wierenga, H. K., and H. Hopster. 1991. Behaviour of dairy cows when fed concentrates with an automatic feeding system. Appl. Anim. Behav. Sci. 30:233-246.

Winter, A., R. M. Teverson, and J. E. Hillerton. 1992. The effect of increased milking frequency and automated milking systems on behavior of dairy cows. Pages 261-269 in Proc. Int. Symp. Prospects for Automatic Milking. A. H. Ipema, A. C. Lippus, J. H. M. Metz, and W. Rossing eds., EAAP Publ. No. 65 Pudoc, Wageningen, The Netherlands. 